\title{
Desempenho de Três Grupos Genéticos de Frangos de Corte Alimentados com Rações Contendo Diferentes Teores de Proteína ${ }^{1}$
}

\author{
Joceli Souza Lisboa ${ }^{2}$, Dirceu Jorge da Silva ${ }^{3}$, Martinho de Almeida e Silva ${ }^{4}$, Paulo Rubens \\ Soares $^{3}$, Altair Soares das Graças ${ }^{3}$
}

\begin{abstract}
RESUMO - O objetivo deste experimento foi avaliar o desempenho de três grupos genéticos de frangos de corte obtidos na UFV, denominados UFV1, UFV2 e UFV3, alimentados com rações contendo diferentes níveis de proteína bruta (PB). Duzentos e quarenta pintos de cada grupo genético, no total de 720 pintos, foram alojados em 48 boxes até 42 dias de idade. Na fase inicial (1 a 21 dias), foi fornecida ração única para todas as aves. Na fase final (22 a 42 dias), as aves passaram a receber rações isoenergéticas (3.100 kcal EM/ $\mathrm{kg}$ ), com diferentes níveis de PB (16,5; 18,0;19,5; e 21,0\%). As características estudadas foram: consumo de ração (CR), ganho de peso (GP) e conversão alimentar (CA) nos períodos de 1 a 21, 22 a 42 e 1 a 42 dias de idade. O delineamento experimental no período inicial foi inteiramente casualizado, com três grupos genéticos e 16 repetições, e para o período final, arranjo fatorial 3x4 (grupo genético e nível de proteína), com quatro repetições. Houve diferenças entre grupos genéticos para GP e CR. O grupo UFV1 apresentou os melhores resultados. A conversão alimentar não diferiu entre os grupos. O aumento do nível de PB influenciou o desempenho das aves. Efeito linear positivo entre níveis de PB, GP e CA foi observado. Consumo de ração não foi influenciado pelos níveis de PB. Não se observou interação entre grupos genéticos e níveis de proteína.
\end{abstract}

Palavras-chave: frangos de corte, grupos genéticos, níveis de proteína

\section{Performance of Three Genetic Groups of Broilers Chicks Fed Diets with Different Protein Levels}

\begin{abstract}
The objective of this experiment was to evaluate the performance of three genetic groups of broiler chicks, obtained at UFV, called UFV1, UFV2 and UFV3, fed diets with different crude protein (CP) levels. Two hundred and forty chicks of each genetic group, totaling 720 chicks, were allotted to 48 floor pens up to 42 days of age. At the initial phase ( 1 to 21 days), all chicks were fed an unique diet. At the final phase (22 to 42 days), the chicks were fed isocaloric diets $(3.100 \mathrm{kcal} \mathrm{ME} / \mathrm{kg}$ ) with different CP levels (16.5, 18.0, 19.5, and 21.0\%). The studied traits were: feed intake (FI), weight gain (WG) and feed:gain ratio (FG) in the periods from 1 to 21,22 to 42 and 1 to 42 days. The experiment design at the initial phase was a completely randomized design, with three genetic groups and sixteen replicates, and for the final phase, a $3 \times 4$ factorial arrangement (genetic group and protein level) with four replicates. There were differences among genetic groups for FI and WG. The UFV1 group showed the best results. The feed:gain ratio did not differ among the groups. The increase in the protein levels affected the broiler chicks performance. A positive linear effect of CP levels on WG and FG was observed. Protein levels did not influenced FI. No interaction was observed between genetic group and protein level.
\end{abstract}

Key Words: broilers, genetic groups, protein levels

\section{Introdução}

A avaliação constante de diferentes linhagens de frangos de corte é de fundamental importância para obtenção de dados atualizados e identificação de linhagens com características produtivas e retornos econômicos mais eficientes e que melhor atendam as necessidades e finalidades do produtor, da indústria e do mercado consumidor.

Segundo BILGILI et al. (1992), idade ao abate, sexo e linhagem são os principais fatores que interferem no desempenho de frangos de corte, entretanto, nutrição, manejo e fatores sanitários também influem no desempenho das aves.

Pesquisadores têm mostrado que a constituição genética parece ser um dos fatores capaz de promover maiores alterações no desempenho das aves.

SOARES et al. (1991), ao compararem o desempenho de quatro marcas comerciais de frangos de corte, observaram diferenças no desempenho e veri-

\footnotetext{
${ }^{1}$ Parte da Tese de Mestrado do primeiro autor, parcialmente financiada pelo CNPQ.

2 Médica Veterinária (Mestrado - UFV).

3 Professor do DZO - UFV.

${ }^{4}$ Professor da UENF.
} 
ficaram que as diferenças apresentadas pelos frangos das diferentes marcas comerciais utilizadas poderiam ser atribuídas a variações genéticas.

Tamanho corporal, taxa de crescimento e produção de ovos são determinados pela genética. Assim, se as aves de grupos genéticos diferentes crescem em taxas diferentes, a exigência de nutrientes entre elas também deve diferir, o que ocorre, provavelmente, em função das diferenças na eficiência da digestão, da absorção de nutrientes e do metabolismo dos nutrientes absorvidos (NRC, 1994). Portanto, todo programa de melhoramento genético deve ser acompanhado de um programa nutricional, adequando os nutrientes às exigências de cada linhagem, propiciando máximo aproveitamento dos ganhos genéticos.

Por isso, muitos trabalhos têm sido conduzidos para identificar níveis protéicos adequados para frangos de corte, a fim de maximizar respostas biológicas e retornos econômicos.

Pesquisando níveis ótimos de proteína na fase de crescimento das aves, FANCHER e JENSEN (1989) utilizaram cinco rações isocalóricas contendo: 22,6; 18,$2 ; 15,7 ; 14,2 ;$ e $12,3 \%$ de PB e verificaram que o ganho de peso e a eficiência alimentar elevaram-se com o aumento do nível protéico da ração e que o consumo não foi influenciado pelos tratamentos.

MORAN JR. et al. (1992) compararam o desempenho de frangos de corte, alimentados com rações em que os níveis de proteína bruta foram reduzidos de 23 para $20 \%$ e de 20 para $17 \%$, nas fases inicial e final, respectivamente. A redução do nível protéico não influenciou o desempenho na fase inicial, entretanto, o ganho de peso e a conversão alimentar pioraram, no período final (21 a 42 dias), quando a proteína foi reduzida.

Dietas com baixos níveis protéicos são prejudiciais para o desempenho de frangos de corte (FANCHER e JENSEN, 1989). Entretanto, UZU (1982), STILBORN e WALDROUP (1988) e SUMMERS et al. (1988) verificaram que a suplementação de dietas de baixos teores protéicos com metionina e lisina resultou em ganho de peso semelhante ao produzido por dietas mais protéicas.

O objetivo da presente pesquisa foi avaliar o desempenho e determinar os níveis adequados de proteína para otimização do ganho de peso e conversão alimentar de três grupos genéticos de frangos de corte produzidos na Universidade Federal de Viçosa (UFV).

\section{Material e Métodos}

O experimento teve duração de 42 dias e foi conduzidona Seçãode Avicultura do Departamento deZootecnia (DZO) da Universidade Federal de Viçosa (UFV), no período de 18 de outubro a 30 de novembro de 1994.

Foram utilizados 720 pintos de 1 dia, não sexados, de três grupos genéticos de frangos de corte, denominados UFV1, UFV2 e UFV3, provenientes de cruzamentos entre linhagens obtidas na Granja de Melhoramento Genético do DZO/UFV. Os pintos de 1 dia foram obtidos a partir de ovos de matrizes de mesma idade (34 semanas) e incubados na Seção de Avicultura do DZO, em idênticas condições.

As aves foram alojadas em galpão de alvenaria, dividido em 48 boxes de 2,0 x 1,0 m, sobre cama de cepilho de madeira, com pé direito de $3,0 \mathrm{~m}$, coberto com telha de amianto, com lanternim e piso de cimento. Foram alojados 15 aves por boxe.

A composição das rações experimentais, de acordo com ROSTAGNO (1990), encontra-se na Tabela 1. No período de 1 a 21 dias, foi fornecida ração com $21,5 \%$ de $\mathrm{PB}$ e $3000 \mathrm{kcal} \mathrm{EM} / \mathrm{kg}$ para todas as unidades experimentais. A partir do $22^{\circ}$ dia, as aves dos três grupos genéticos foram subdivididas em quatro parcelas que passaram a receber rações isoenergéticas $(3100 \mathrm{kcal} \mathrm{EM} / \mathrm{kg}$ ) com 16,5; 18,0; 19,5; e 21,0\% de PB, suplementadas com metionina e/ ou lisina, quando necessário, para evitar deficiências, sendo estes níveis corrigidos em relação ao teor de energia da ração.

O delineamento experimental foi inteiramente casualizado, envolvendo na fase inicial (1 a 21 dias) três grupos genéticos com 16 repetições e 15 aves por unidade experimental. Na fase final (22 a 42 dias), utilizou-se esquema fatorial 3 x 4 (três grupos genéticos e quatro níveis de PB), com quatro repetições e 15 aves por unidade experimental.

Foram estudadas as seguintes variáveis: consumo de ração, ganho de peso e conversão alimentar nos períodos de 1 a 21, 22 a 42 e 1 a 42 dias de idade.

Para análises estatísticas das variáveis estudadas, utilizou-se o sistema para Análises Estatísticas e Genéticas (SAEG), desenvolvido na UFV (1982). As comparações entre médias foram feitas pelo teste de Newman Keuls a 5\%. Os graus de liberdade dos níveis de proteína da fase final foram decompostos nos efeitos linear, quadrático e cúbico. 


\section{Resultados e Discussão}

As médias de consumo de ração, ganho de peso e conversão alimentar das aves dos grupos genéticos UFV1, UFV2 e UFV3, nos períodos de 1 a 21, 22 a 42 e 1 a 42 dias de idade, são apresentadas na Tabela 2.

Não houve interação significativa entre grupos genéticos e níveis de proteína. A análise de variância mostrou diferenças significativas entre grupos genéticos para consumo de ração $(\mathrm{P}<0,05)$ e ganho de peso $(\mathrm{P}<0,01)$, não sendo observada diferença entre os grupos para conversão alimentar. Com relação ao consumo de ração, no período de 1 a 21 dias, não houve diferença entre os grupos genéticos UFV1 e UFV2, nem entre UFV2 e UFV3. Contudo, as aves do grupo UFV1 apresentaram maior consumo que as do grupo UFV3. Comportamento similar entre grupos foi observado para ganho de peso nesse mesmo período. Para os períodos de 22 a 42 dias e 1 a 42 dias de idade, as médias de consumo de ração dos grupos UFV1 e UFV2 não diferiram entre si, mas foram superiores à média do grupo UFV3. O grupo UFV1 obteve maior ganho de peso e o grupo UFV3, o menor. O grupo UFV2 apresentou valor intermediário entre UFV1 e UFV3. A conversão alimentar não diferiu entre os grupos genéticos, uma vez que o grupo que consumiu mais ração também ganhou mais peso.

Estes resultados estão de acordo com as pesquisas de ABREU (1982), BILGILI et al. (1992), SOUZA et al. (1993) e MENDES et al. (1993), que também encontraram diferenças em algumas das características de desempenho de diferentes linhagens ou cruzamentos.

BILGILI et al. (1992) concluíram que as variações encontradas para desempenho podem ser atribuídas às diferentes taxas de crescimento, apresentadas pelas linhagens, o que deve influir, significa-

Tabela 1 -Composição percentual das rações experimentais Table 1 - Percentage composition of experimental diets

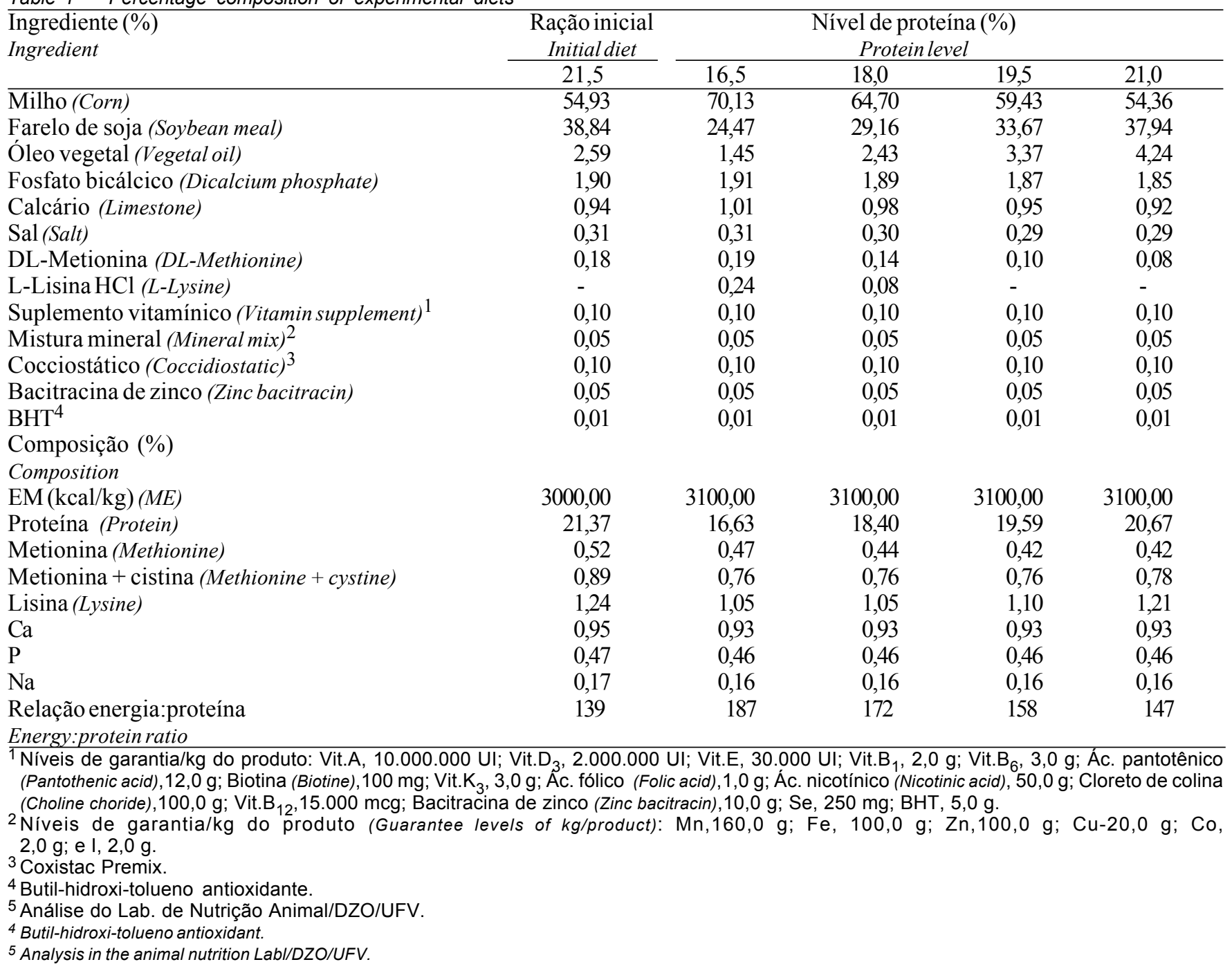


LISBOA et al.

Tabela 2 - Média de consumo de ração (CR), ganho de peso (GP) e conversão alimentar (CA) dos grupos genéticos nos períodos de 1 a 21, 22 a 42 dias e 1 a 42 dias de idade

Table 2 - Average feed intake (FI), weight gain (WG) and feed:gain ratio (FG) of genetic groups in the periods from 1 to 21, 22 to 42 and 1 to 42 days of age

\begin{tabular}{|c|c|c|c|c|c|c|c|c|c|}
\hline \multirow{3}{*}{$\begin{array}{l}\text { Grupo genético } \\
\text { Genetic group }\end{array}$} & CR $(\mathrm{g})$ & GP $(\mathrm{g})$ & $\mathrm{CA}(\mathrm{g} / \mathrm{g})$ & $\mathrm{CR}(\mathrm{g})$ & GP(g) & $\mathrm{CA}(\mathrm{g} / \mathrm{g})$ & $\mathrm{CR}(\mathrm{g})$ & $\mathrm{GP}(\mathrm{g})$ & $\begin{array}{c}\mathrm{CA}(\mathrm{g} / \mathrm{g}) \\
F G\end{array}$ \\
\hline & $F I$ & $W G$ & $F G$ & $F I$ & $W G$ & $F G$ & $F I$ & $W G$ & $F G$ \\
\hline & \multicolumn{3}{|c|}{1 a 21 dias } & \multicolumn{3}{|c|}{22 a 42 dias } & \multicolumn{3}{|c|}{1 a 42 dias } \\
\hline UFV2 & $935 \mathrm{ab}$ & $597 \mathrm{ab}$ & $1,56 \mathrm{a}$ & $2727 \mathrm{a}$ & $1269 \mathrm{~b}$ & $2,15 \mathrm{a}$ & $3662 a$ & $1866 \mathrm{~b}$ & $1,96 \mathrm{a}$ \\
\hline UFV3 & $923 b$ & $585 \mathrm{~b}$ & $1,58 \mathrm{a}$ & $2624 \mathrm{~b}$ & $1225 \mathrm{c}$ & $2,14 \mathrm{a}$ & $3548 \mathrm{~b}$ & $1810 \mathrm{c}$ & $1,96 \mathrm{a}$ \\
\hline $\mathrm{CV}(\%)$ & 3,82 & 4,19 & 2,98 & 3,41 & 3,81 & 2,44 & 3,28 & 3,68 & 2,10 \\
\hline
\end{tabular}

Médias, na coluna, seguidas de letras diferentes são diferentes $(P<0,05)$ pelo teste Newman Keuls.

Means, within a column, followed by different letter are different $(P<.05)$ by Newman Keuls test.

Tabela 3 - Média de consumo de ração (CR), ganho de peso (GP) e conversão alimentar (CA) nos períodos de 22 a 42 dias e de 1 a 42 dias de idade, de acordo com os níveis de proteína da ração

Table 3 - Average feed intake (FI), weight gain (WG) and feed:gain ratio (FG) in the periods from 22 to 42 days and from 1 to 42 days of age, on the dietary protein levels

\begin{tabular}{|c|c|c|c|c|c|c|}
\hline \multirow[t]{2}{*}{$\begin{array}{l}\text { Nível de proteína } \\
\text { Protein level }\end{array}$} & $\begin{array}{c}\mathrm{CR}(\mathrm{g}) \\
F I\end{array}$ & $\begin{array}{c}\mathrm{GP}(\mathrm{g}) \\
W G\end{array}$ & $\begin{array}{c}\mathrm{CA}(\mathrm{g} / \mathrm{g}) \\
F G\end{array}$ & $\begin{array}{c}\mathrm{CR}(\mathrm{g}) \\
F I \\
\end{array}$ & $\begin{array}{c}\text { GP(g) } \\
W G \\
\end{array}$ & $\begin{array}{c}\mathrm{CA}(\mathrm{g} / \mathrm{g}) \\
F G\end{array}$ \\
\hline & \multicolumn{3}{|c|}{22 a 42 dias } & \multicolumn{3}{|c|}{1 a 42 dias } \\
\hline$\overline{16,5}$ & 2734 & 1238 & 2,21 & 3674 & 1840 & 1,99 \\
\hline 18,0 & 2710 & 1258 & 2,15 & 3642 & 1853 & 1,96 \\
\hline 19,5 & 2709 & 1280 & 2,11 & 3653 & 1880 & 1,94 \\
\hline 21,0 & 2690 & 1297 & 2,07 & 3629 & 1895 & 1,91 \\
\hline
\end{tabular}

${ }^{1}$ Efeito linear $(P<0,01)$ (Linear effect $\left.[P<.01]\right)$.

${ }^{2}$ Efeito linear $(P<0,05)$ (Linear effect $\left.[P<.05]\right)$.

tivamente, no consumo de ração, no ganho de peso e na conversão alimentar. Não se observou efeito significativo da interação do grupo genético x nível de proteína para nenhuma das características estudadas.

$\mathrm{Na}$ Tabela 3 são apresentados os resultados de consumo de ração, ganho de peso e conversão alimentar, nos períodos de 22 a 42 dias e 1 a 42 dias, de acordo com os níveis de proteína da ração.

$\mathrm{Na}$ Tabela 4 são apresentadas as equações de regressão das variáveis influenciadas pelo nível de proteína das rações. Houve efeito linear dos níveis de proteína para ganho de peso e conversão alimentar. No período de 22 a 42 dias, o ganho de peso $\left(\hat{\mathrm{Y}}=1020,25+13,2500 \mathrm{X}, \mathrm{R}^{2}=1,00\right)$ aumentou $(\mathrm{P}<0,01)$ e a conversão alimentar $(\hat{\mathrm{Y}}=2,68727$ $\left.0,292372 X, \mathrm{R}^{2}=0,99\right)$ melhorou $(\mathrm{P}<0,01)$, linearmente, com o aumento do nível de proteína da ração. No período de 1 a 42 dias, o aumento do nível de proteína da ração também proporcionou incremento no ganho de peso $(\mathrm{P}<0,05)$ e melhoria linear na conversão alimentar $(\mathrm{P}<0,01)$, segundo as equações $\hat{\mathrm{Y}}=1630,00$ $+12,6611 \mathrm{X}, \mathrm{R}^{2}=0,98$ e $\hat{\mathrm{Y}}=2,28626-0,0176339 \mathrm{X}$, $\mathrm{R}^{2}=1,00$, respectivamente. Os níveis de proteína bruta utilizados não influenciaram o consumo de ração. Estes resultados estão de acordo com os de ABREU (1982) e DIAMBRA e McCARTNEY (1985), que verificaram melhoria no desempenho das aves, quando utilizaram níveis crescentes de proteína na fase final de criação de frangos de corte. FANCHER e JENSEN (1986) também encontraram relação positiva entre níveis de proteína da ração, ganho de peso e conversão alimentar.

A redução no crescimento das aves e a má conversão alimentar, associadas às rações com menores níveis protéicos, podem ser atribuídas ao desbalanceamento de aminoácidos.

As suplementações com metionina e lisina, considerados como primeiro e segundo aminoácidos limitantes para aves, foram feitas de maneira a atingir os níveis mínimos adequados, em função do nível de energia, contida nas rações utilizadas. Porém, desconsiderou-se a correção de outro aminoácido limitante, a treonina, que se mostrou deficiente nas rações de menores teores protéicos. Sabe-se que a utilização da proteína pode ser limitada pela deficiência de algum aminoácido, tendo em vista que desproporção aminoacídica reduz a síntese de proteína. Assim, a redução de crescimento das aves, observa- 
Tabela 4 - Regressão de ganho de peso e conversão alimentar em relação ao nível de proteína das ração

Table 4 - Regression of weight gain and feed:gain ratio on protein level of diet

\begin{tabular}{lll}
\hline Parâmetro & $\begin{array}{l}\text { Regressão } \\
\text { Regression }\end{array}$ & $\mathrm{R}^{2}$ \\
\hline Parameter & & \\
\hline
\end{tabular}

Ganho de peso

Weight gain

1 a 42 dias $^{2}$

22 a 42 dias $^{1}$

$\hat{\mathrm{Y}}=1630,00+12,6611 \mathrm{X}$

0,98

$\hat{\mathrm{Y}}=1020,25+13,2500 \mathrm{X}$

1,00

Conversão alimentar

Feed:gain ratio

1 a 42 dias $^{2}$

22 a 42 dias $^{1}$

$\hat{\mathrm{Y}}=2,28626-0,0176339 \mathrm{X} \quad 1,00$

${ }_{1}^{1}(\mathrm{P}<0,01)$.

$2(\mathrm{P}>0,05)$

da nas rações menos protéicas, resultou do desbalanceamento de aminoácidos e tornou-se menos severa, à medida que o teor de proteína da ração aumentou, uma vez que as quantidades de aminoácidos limitantes elevaram-se, concomitantemente com o aumento do teor de proteína bruta, proporcionando aumento na utilização dos aminoácidos para síntese protéica no organismo.

\section{Conclusões}

O desempenho de frangos de corte variou com o grupo genético e o nível de proteína da ração. O grupo UFV1 apresentou o melhor desempenho e existiu relação positiva entre nível de proteína da ração, ganho de peso e conversão alimentar.

Não foi possível determinar o nível de PB na ração para otimizar o desempenho das aves, entretanto, observou-se que os grupos genéticos de frangos de corte estudados são muito exigentes em proteína.

\section{Referências Bibliográficas}

ABREU, R.D. Comportamento de híbridos comerciais de frangos de corte sob dietas com diferentes niveis de proteina. Viçosa, MG, UFV, 1982. 58p. Dissertação (Mestrado em Zootecnia) - Universidade Federal de Viçosa, 1982.

BILGILI, S.F., MORAN JR., E.T., ACAR, N. 1992. Strain-cross response of male broilers to dietary lysine in the finisher feed: live performance and further - processing Yields. Poult. Sci., 71(5):850-858.

DIAMBRA, O.H., McCARTNEY, M.G. 1985. The effects of low protein finisher diets on broiler males performance and abdominal fat. Poult. Sci., 64(10):2013-2015.

FANCHER, B.I., JENSEN, L.S. 1986. Effects of feeding reduced dietary protein upon broilers from 3 to 6 weeks of age while maintaining essential amino acid requirements. Poult. Sci., 65:40 (Suppl.1).

FANCHER, B.I., JENSEN, L.S. 1989. Male broiler performance during the starting and growing periods as affected by dietary protein, essential amino acids, and potassium levels. Poult. Sci., 68(10):1385-1395.

MENDES, A.A., GARCIA, E.A., GONZALES, E. et al. 1993. Efeito da linhagem e idade de abate sobre o rendimento de carcaça de frangos de corte. R. Soc. Bras. Zootec., 22(3):466-472.

MORAN JR., E.T., BUSHONG, R.D., BILGILI, S.F. 1992. Reducing dietary crude protein for broilers while satisfying amino acid requirements by least-cost formulation: live performance, litter composition, and yield of fast-foodcarcass cuts at six weeks. Poult. Sci., 71(10):1687-1694.

NATIONAL RESEARCH COUNCIL - NRC. 1994. Nutrient requirements of poultry. 9. ed. Washington, D.C.: National Academic Press. 155p.

ROSTAGNO, H.S. Valores de composição de alimentos e de exigências nutricionais utilizados na formulação das rações para aves. In: SOCIEDADE BRASILEIRA DE ZOOTECNIA. Avicultura. Piracicaba, 1990. p. 11-30

SOARES, P.R., FONSECA, J.B., SILVA, M.A. et al. 1991. Comportamento de quatro marcas comerciais de frangos de corte em diferentes densidades. R. Soc. Bras. Zootec., 20(1):74-79.

SOUZA, P.A., SOUZA, H.B.A., BROGNONI, E. et al. Desempenho e características de carcaças de diferentes linhagens de frangos de corte. In: CONFERÊNCIA APINCO DE CIÊNCIA E TECNOLOGIA AVÍCOLA, 1993, Santos. Anais... Santos: APINCO, 1993. p.84

STILBORN, H.L., WALDROUP, P.W. 1988. Minimum levels of dietary protein for growing broilers. Poult. Sci., 67:36 (Suppl.1).

SUMMERS, J.D., LEESON, S., SPRATT, D. 1988. Yield and composition of edible meat fron male broiler as influenced by dietary protein level and amino acid supplementation. Can. J. Anim. Sci., 8(1):241-248.

UNIVERSIDADE FEDERAL DE VIÇOSA. Central de Processamento de Dados - UFV/CPD. SAEG - Sistema para Análise Estatística. Viçosa, MG, 1982. 59p.

UZU, G. 1982. Limiting of redution of the protein level in broiler feeds. Poult. Sci., 61(7):1577-1578.
Recebido em: 17/03/97

Aceito em: 07/12/98 